Pacific Journal of Mathematics

INTEGRAL INEQUALITIES OF WIRTINGER-TYPE AND
FOURTH-ORDER ELLIPTIC DIFFERENTIAL INEQUALITIES 


\title{
INTEGRAL INEQUALITIES OF WIRTINGER-TYPE AND FOURTH-ORDER ELLIPTIC DIFFERENTIAL INEQUALITIES
}

\section{PUI-KeI WONG}

\begin{abstract}
A generalized Riccati transformation is used to transform a fourth-order elliptic differential inequality. From this an integral relation is derived which includes as special case an inequality of the Wirtinger-type. This Wirtinger inequality is then used to prove a Sturmian comparison theorem for fourth order quasilinear elliptic differential inequalities.
\end{abstract}

Integral inequalities of the Wirtinger-type for a real-valued function of a real variable have the form

$$
\int_{a}^{b} u^{\prime 2} d x \geqq \int_{a}^{b} p(x) u^{2} d x,
$$

where $p(x)$ is a function defined and continuous on $[a, b]$ and $u$ is any member of some suitable admissible class, c.f. [10], p. 185. In [3] Beesack utilized certain self-adjoint ordinary differential equations of the second and fourth order to generate other inequalities of type (1) and

$$
\int_{a}^{b} u^{\prime \prime 2} d x \geqq \int_{a}^{b} p(x) u^{2} d x
$$

Coles [7] then extended some of these to include inequalities of the form

$$
0 \leqq \sum_{k=0}^{n}(-1)^{n+k} \int_{a}^{b} f_{k}(x)\left[u^{(k)}\right]^{2} d x
$$

On p. 498 of Beesack's paper [3], one finds also the integral identity

$$
\int_{G} \int\left(u_{x}^{2}+u_{y}^{2}-p u^{2}\right) d A=\int_{G}\left(u_{x}-g u\right)^{2} d A+\int_{G}\left(u_{y}-h u\right)^{2} d A,
$$

which is associated with the equation $v_{x x}+v_{y y}+p(x, y) v=0$. Since the quantity on the right is always nonnegative, this relation leads immediately to a two-dimensional analog of (1). Such inequalities were later obtained by Benson [4] and Calvert [5]. An n-dimensional analog of (2) was given by Calvert in [6].

Following Beesack's method this author [17] has recently obtained some Wirtinger-type inequalities analogous to (1) for matrix functions of several variables. These were obtained through the use of a certain generalized Riccati transformation associated with an elliptic system 
of the second order. In this paper we shall establish an analog of inequality (2) by considering an elliptic inequality of the fourth order. The resulting Wirtinger-type inequality, which generalizes the earlier result of Calvert [6], is then used to prove a comparison theorem between two selfadjoint quasilinear elliptic equations of the fourth order. Finally we conclude by extending this comparison theorem to include a special class of nonselfadjoint fourth order operators. Earlier Swanson [15] had proved a comparison theorem for linear elliptic operators of order $2 \mathrm{~m}$. More recently Diaz and Dunninger [8] and Dunninger [9] have also considered comparison theorems for fourth order linear elliptic equations of the form

$$
\Delta[a(x) \Delta u]-p(x) u=0,
$$

where $a(x)$ and $p(x)$ are scalar-valued functions.

Let $G$ be a bounded domain of $n$-dimensional Euclidean space $R^{n}$ with piecewise smooth boundary $\partial G$. A variable point of $R^{n}$ will be denoted by $x=\left(x_{1}, \cdots, x_{n}\right)$, and we adopt the following differentiation notation:

$$
\begin{aligned}
& \frac{\partial u}{\partial x_{i}}=D_{i} u, \\
& D_{i}\left(D_{j} u\right)=D_{i j} u, \quad i, j=1, \cdots, n .
\end{aligned}
$$

Let $A=A(x, u)=\left(A^{i j}(x, u)\right)$ and $B=B(x, u)=\left(B^{i j}(x, u)\right)$ be two real symmetric $n \times n$ matrix functions defined on $\bar{G} \times R$ such that $A \in C^{2}$ and $B \in C^{1}$. Suppose $p=p(x, u)$ is a given real continuous function and $\sigma=\sigma(x, u)=\left(\sigma^{1}(x, u), \cdots, \sigma^{n}(x, u)\right)$ is a given continuous $n$-vector field on $\bar{G} \times R$. We consider the real quasilinear differential inequality of the fourth order

$$
D_{h i}\left[A^{h i}\left(A^{j k} D_{j k} u\right)\right]-D_{i}\left(B^{i j} D_{j} u\right)-2 \sigma^{i} D_{i} u-p u \geqq 0 .
$$

Here, and in what follows, we have adopted the Einstein summation convention indicated below to shorten the computational formulas:

$$
\begin{aligned}
& D_{h i}\left[A^{h i}\left(A^{j h} D_{j k} u\right)\right]=\sum_{h, i, j, k=1}^{n} D_{h i}\left[A^{h i}\left(A^{j k} D_{j k} u\right)\right], \\
& D_{i}\left(B^{i j} D_{j} u\right)=\sum_{i, j=1}^{n} D_{i}\left(B^{i j} D_{j} u\right), \\
& \sigma^{i} D_{i} u=\sum_{i=1}^{n} \sigma^{i} D_{i} u .
\end{aligned}
$$

LEMma 1. Suppose $u$ is a solution of (3) such that $u(x)>0$ in G. Set 


$$
\left\{\begin{array}{l}
v_{k}=u^{-1} D_{k} u, \quad v=\left(v_{1}, \cdots, v_{n}\right), \\
z_{j k}=D_{j} v_{k}+v_{j} v_{k}, \quad Z=\left(z_{j k}\right), \\
j, k=1, \cdots, n .
\end{array}\right.
$$

Then $v$ and $Z$ will satisfy

$$
\begin{aligned}
p \leqq & D_{h i}\left[A^{h i}\left(A^{j k} z_{j k}\right)\right]+\left(A^{j k} z_{j k}\right)^{2}+2 v_{h} D_{i}\left[A^{h i}\left(A^{j k} z_{j k}\right)\right] \\
& -D_{i}\left(B^{i j} v_{j}\right)-2 \sigma^{i} v_{i}-v_{i} B^{i j} v_{j} .
\end{aligned}
$$

Proof. To verify (5) we merely note that a direct calculation on (4) yields the following identities:

$$
\begin{gathered}
u^{-1} D_{j k} u=z_{j k}, \\
u^{-1} D_{i}\left[A^{h i}\left(A^{j k} D_{j k} u\right)\right]=D_{i}\left[A^{h i}\left(A^{j k} z_{j k}\right)\right]+A^{h i} v_{i} A^{j k} z_{j k}, \\
u^{-1} D_{h i}\left[A^{h i}\left(A^{j k} D_{j k} u\right)\right]=D_{h i}\left[A^{h i}\left(A^{j k} z_{j k}\right)\right]+\left(A^{j k} z_{j k}\right)^{2} \\
+2 v_{h} D_{i}\left[A^{h i}\left(A^{j k} z_{j k}\right)\right], \\
u^{-1} D_{i}\left(B^{i j} D_{j} u\right)=D_{i}\left(B^{i j} v_{j}\right)+v_{i} B^{i j} v_{j} .
\end{gathered}
$$

Combining (3) with (6c) and (6d) we arrive immediately at (5).

We shall call (4) a generalized Riccati transformation and (5) the Riccati inequation associated with (3). Before stating our first result we shall introduce the following functionals:

$$
\begin{aligned}
M_{1}(w, Z)= & \int_{G}\left[A^{j k}\left(D_{j k} w-w z_{j k}\right)\right]^{2} d x, \\
M_{2}(w, v)= & \int_{G} B^{i j}\left(D_{i} w-w v_{i}\right)\left(D_{j} w-w v_{j}\right) d x, \\
Q(w, u)= & \int_{G}\left[\left(A^{j k} D_{j k} w\right)^{2}+B^{i j} D_{i} w D_{j} w-p w^{2}\right] d x, \\
T(w: v, Z)= & 2 \int_{G} A^{h i}\left(D_{h} w-w v_{h}\right)\left(D_{i} w-w v_{i}\right) A^{j k} z_{j k} d x, \\
\gamma(w: v, Z)= & \int_{\partial G}\left[w^{2} \eta_{h} D_{i}\left(A^{h i} A^{j k} z_{j k}\right)+2 w^{2} A^{h i} v_{h} \eta_{i} A^{j k} z_{j k}\right] d s \\
& -\int_{\partial G}\left[2 w A^{h i} \eta_{i} D_{h} w A^{j k} z_{j k}+w^{2} \eta_{i} B^{i j} v_{j}\right] d S,
\end{aligned}
$$

where $\eta=\left(\eta_{1}, \cdots, \eta_{n}\right)$ denotes the outward pointing unit normal on the boundary $\partial G$ and $w$ is any member of the class

$$
\Omega=\left\{w \in C^{1}(\bar{G}) \cap C^{2}(\mathrm{G}): \int_{G}\left(A^{j k} D_{j k} w\right)^{2} d x<\infty\right\} .
$$

We also point out that the functional $M_{1}$ defined by (7) is always nonnegative.

Theorem 2. Let $u$ be a positive solution of (3) in $G$ and let $v$ 
and $Z$ be defined by (4). Then for all $w \in \Omega$,

$$
\begin{gathered}
\\
Q(w, u)+T(w: v, Z)+\gamma(w: v, Z) \\
\geqq M_{1}(w, Z)+M_{2}(w, v)+2 \int_{G} w^{2} \sigma \cdot v d x .
\end{gathered}
$$

Proof. Using the symmetry of $A$ we can expand the right hand side of (7) and get

$$
\begin{aligned}
M_{1}(w, Z)= & \int_{G}\left[\left(A^{j k} D_{j k} w\right)^{2}+w^{2}\left(A^{j k} z_{j k}\right)^{2}\right] d x \\
& -2 \int_{G} w\left(A^{h i} D_{h i} w\right) A^{j k} z_{j k} d x .
\end{aligned}
$$

The last integral in (13), which we shall denote by $I$, can be integrated with the help of the identities

$$
\begin{aligned}
D_{h}\left[A^{h i}\left(w D_{i} w\right) A^{j k} z_{j k}\right]= & \left(A^{h i} D_{h} w D_{i} w\right) A^{j k} z_{j k}+\left(w A^{h i} D_{h i} w\right) A^{j k} z_{j k} \\
& +w D_{h}\left[\left(A^{j k} z_{j k}\right) A^{h i}\right] D_{i} w
\end{aligned}
$$

and

$$
D_{h}\left[w^{2} D_{i}\left(A^{j k} z_{j_{k}} A^{h i}\right)=2 w D_{h} w D_{i}\left(A^{j k} z_{j k} A^{h i}\right)+w^{2} D_{h i}\left(A^{j k} z_{j k} A^{h i}\right) .\right.
$$

Using the divergence theorem of Gauss, one finds that

$$
I=\int_{G}\left[2\left(A^{h i} D_{h} w D_{i} w\right) A^{j k} z_{j k}-w^{2} D_{h i}\left(A^{j k} z_{j k} A^{h i}\right)\right] d x+\gamma_{1}(w, Z),
$$

where

$$
\gamma_{1}(w, Z)=\int_{\partial G}\left[w^{2} \eta_{h} D_{i}\left(A^{j k} z_{j k} A^{h i}\right)-2 w\left(A^{h i} \eta_{i} D_{h} w\right) A^{j k} z_{j k}\right] d S .
$$

Putting this into (13) we get

$$
\begin{aligned}
M_{1}= & \gamma_{1}+\int_{G}\left[\left(A^{j k} D_{j k} w\right)^{2}+w^{2}\left\{\left(A^{j k} z_{j k}\right)^{2}+D_{h i}\left(A^{j k} z_{j k} A^{h i}\right)\right\}\right] d x \\
& +2 \int_{G}\left(A^{h i} D_{h} w D_{i} w\right) A^{j k} z_{j k} d x .
\end{aligned}
$$

Using the identity

$$
D_{i}\left(w^{2} B^{i j} v_{j}\right)=w^{2} D_{i}\left(B^{i j} v_{j}\right)+2 w B^{i j} v_{j} D_{i} w,
$$

one finds by a similar application of the divergence theorem that

$$
\begin{aligned}
M_{2}= & \int_{G}\left[B^{i j} D_{i} w D_{j} w+w^{2}\left\{D_{i}\left(B^{i j} v_{j}\right)+B^{i j} v_{i} v_{j}\right\}\right] d x \\
& -\int_{\partial G} w^{2}(\eta \cdot B v) d S .
\end{aligned}
$$


Adding (14) and (15) and rearranging terms with the help of (5), we get

$$
M_{1}+M_{2}+2 \int_{G} w^{2}(\sigma \cdot v) d x \leqq Q(w, u)+\gamma_{2}(w: v, Z)+J(w: v, Z)
$$

where

$$
\gamma_{2}(w: v, Z)=\gamma_{1}(w, Z)-\int_{\partial G} w^{2}(\eta \cdot B v) d S
$$

and

$$
\begin{aligned}
J(w: v, Z)= & 2 \int_{G} w^{2}\left[\left(A^{j k} z_{j k}\right)^{2}+v_{h} D_{i}\left(A^{j k} z_{j k} A^{h i}\right)\right] d x \\
& +2 \int_{G}\left(A^{h i} D_{h} w D_{i} w\right) A^{j k} z_{j k} d x .
\end{aligned}
$$

Using (4) and the divergence theorem, the integral $J$ can be transformed as follows:

$$
\begin{aligned}
J & =2 \int_{G}\left\{A^{h i}\left[D_{h} w D_{i} w+w^{2}\left(D_{i} v_{h}+v_{h} v_{i}\right)\right] A^{j k} z_{j k}+w^{2} v_{h} D_{i}\left(A^{j k} z_{j k} A^{h i}\right)\right\} d x \\
& =2 \int_{G}\left[A^{h i}\left(D_{h} w-w v_{h}\right)\left(D_{i} w-w v_{i}\right) A^{j k} z_{j k}+D_{i}\left(w^{2} A^{h i} v_{h} A^{j k} z_{j k}\right)\right] d x \\
& =T(w: v, Z)+2 \int_{\partial G} w^{2}\left(A^{h i} v_{h} \eta_{i}\right) A^{j k} z_{j k} d S .
\end{aligned}
$$

Putting this back into (16) and collecting the boundary terms, we finally arrive at (12) which is the desired relation.

We remark that when $n=1, A=\left(\delta^{i j}\right), \sigma=B \equiv 0$, and $p=p(x)$, relation (12) reduces to an identity of Beesack [3], p. 488, formula (2.4), for fourth order linear ordinary differential operators. Since in our case, the coefficient $p$ may depend on $u$ as well as $x$, relation (12) is thus applicable to nonlinear equations such as

$$
u^{(i v)}-|u|^{\alpha}=0, \quad \alpha \geqq 1 \text {. }
$$

To facilitate discussion of boundary value problems we shall rewrite the boundary term (11) using the following notation:

$$
u_{\alpha}=\eta_{i} A^{i j} D_{j} u, \quad u_{\beta}=\eta_{i} B^{i j} D_{j} u, \quad L u=A^{i j} D_{i j} u .
$$

Note that when $\left(A^{i j}\right)=\left(\delta^{i j}\right)$, the identity matrix, $L u$ is simply the Laplacian of $u$. In terms of these quantities (11) becomes

$$
\begin{aligned}
\gamma(w, u)= & \int_{\partial G}\left(u^{-1} w^{2}\left\{(L u)_{\alpha}-u_{\beta}+(L u)\left[u^{-1} u_{\alpha}+\eta_{h} D_{i}\left(A^{h i}\right)\right]\right\}\right. \\
& \left.-2 u^{-1} w w_{\alpha} L u\right) d S .
\end{aligned}
$$


CoRollary 3. Suppose that

(H1) $A$ is positive semidefinite;

(H2) $B$ is positive semidefinite; and

(H3) $u$ is a solution of (3) such that $u(x)>0$ and $L u \leqq 0$ in $G$. Then for every $w \in \Omega$,

$$
Q(w, u)+\gamma(w, u) \geqq 2 \int_{G} u^{-1} w^{2}(\sigma \cdot \nabla u) d x,
$$

where $\gamma(w, u)$ is given by (11').

Proof. Since $u$ is a solution of (3) such that $u(x)>0$ in $G$, Lemma 1 and Theorem 2 together imply that (12) holds. Now $M_{1} \geqq 0$ always and $M_{2} \geqq 0$ follows from (H2). Using (6a) and the symmetry of $A$, we can rewrite (10) as

$\left(10^{\prime}\right) T(w, u) \equiv T(w: v, Z)=2 \int_{G} A^{h i}\left(D_{h} w-w v_{h}\right)\left(D_{i} w-w v_{i}\right) u^{-1} L u d x$.

Since $A$ is positive semidefinite (H3) implies that $T(w, u) \leqq 0$ so that (17) follows from (12).

To obtain an inequality of the Wirtinger type analog to (2) we shall replace inequality (3) by the equation

$$
\left\{\begin{array}{l}
K u \equiv D_{h i}\left[\left(A^{j k} D_{j k} u\right) A^{h i}\right]-D_{i}\left(B^{i j} D_{j} u\right)-p u=0, \quad x \in G \\
L u=0, \quad x \in \partial G .
\end{array}\right.
$$

\section{THEOREM 4. Suppose that}

(H1') $A$ is positive definite;

(H2) $B$ is positive semidefinite; and

(H3') $u$ is a solution of (18) such that $u(x)>0$ and $L u<0$ in $G$. Then for every $w \in \Omega$ for which $w=0$ on $\partial G$,

$$
\int_{G}\left[(L w)^{2}+\nabla w \cdot B \nabla w\right] d x \geqq \int_{G} p w^{2} d x,
$$

where equality holds if, and only if, $w \equiv k u, k=$ constant.

Proof. Since $w=0$ on $\partial G$, one sees from $\left(11^{\prime}\right)$ that $\gamma(w, u)=0$. Moreover, since inequality (3) is replaced by the equation in (18), we see that equality must hold in (12) with $\gamma(w, u)=0$ and $\sigma=0$, i.e.,

$$
Q(w, u)+T(w, u)=M_{1}(w, u)+M_{2}(w, u) .
$$

Again $M_{1} \geqq 0$ always while (H2) implies $M_{2} \geqq 0$. Also $T(w, u) \leqq 0$ by (H1') and (H3') so that (19) follows immediately. Clearly equality will hold if, and only if, $T=M_{1}=M_{2}=0$. If $w \equiv k u$, then these quantities are trivially zero. Conversely, if $T_{1}=0$, then $\left(10^{\prime}\right),\left(\mathrm{H} 1^{\prime}\right)$ 
and $\left(\mathrm{H} 3^{\prime}\right)$ together imply that we must have $u D_{i} w \equiv w D_{i} u, i=1, \cdots, n$, and hence that $w \equiv k u$. This proves the assertion.

REMARK 1. We recall that a function $u$ is called a subsolution of (18) if $K u \geqq 0$ in $G$ and $L u=0$ on $\partial G$. Inequality (19) remains valid for subsolutions if we weaken hypothesis $\left(\mathrm{H}^{\prime}\right)$ to $(\mathrm{H} 1)$ and replace (H3) by

(H4) $u$ is a subsolution of (18) such that $u(x)>0$ and $L u \leqq 0$ in $G$. However, the last statement on equality if, and only if, $w \equiv k u$, is no longer true.

REMARK 2. When eq. (18) is linear, condition (H3') will be fulfilled if $u$ is a solution of (18) such that $u(x)>0$ in $G$ and that

$$
\varphi(u)=\nabla \cdot(B \nabla u)+p u-\left(D_{h i} A^{h i}\right) L u \geqq 0,
$$

$\varphi(u) \not \equiv 0$ in $G$. To see this we note that if we let $y=L u$, then (18) becomes

$$
D_{i}\left(A^{i j} D_{j} y\right)+D_{i}\left(A^{i j}\right) D_{j} y=\varphi(u) \geqq 0 .
$$

Since $A$ is positive definite by $\left(\mathrm{H} 1^{\prime}\right)$, it follows from the maximum principle of Hopf $([13]$, p. 64) that $y$ cannot attain a nonnegative maximum $M$ at an interior point of $G$ unless $y \equiv M$. Since $y=L u=0$ on $\partial G$, we have either $y<0$ in $G$ or $y \equiv 0$ in $G$. But if $y \equiv 0$ then, by the last equation, $\varphi \equiv 0$ in $G$, contrary to hypothesis. Hence $y=L u<0$ in $G$.

If in addition we assume $D_{i j}\left(A^{i j}\right) \leqq 0$ in $G$, then condition (20) may be replaced by

$$
F(u)=\nabla \cdot(B \nabla u)+p u \geqq 0,
$$

$F(u) \not \equiv 0$ in $G$, and $\left(\mathrm{H}^{\prime}\right)$ will also be satisfied. This latter condition is clearly fulfilled when $A$ is the identity matrix. The equation in this case is

$$
\Delta^{2} u-\nabla \cdot(B \nabla u)-p u=0 .
$$

REMARK 3. The conclusion of Theorem 4 remains valid if we assume (H1 ) $A$ is positive semidefinite;

$\left(\mathrm{H} 2^{\prime}\right) \quad B$ is positive definite; and

$\left(\mathrm{H}^{\prime \prime}\right) \quad u$ is a solution of (18) such that $u(x)>0$ and $L u \leqq 0$ in $G$.

In this case we may in fact take $A$ to be the null matrix and obtain corresponding results on second order elliptic equations, c.f. [16].

REmark 4. When eq. (18) is linear, i.e., $A=A(x), B=B(x)$ and 
$p=p(x)$, then inequality (19) is recognized as an $n$-dimensional analog of inequality (2). We shall state this fact separately.

Corollary 5. Let $A=A(x), B=B(x)$ and $p=p(x)$ in (18), where $A$ and $B$ are positive semidefinite matrices at least one of which is definite. Suppose $u$ is a solution of (8) such that $u(x) \neq 0$ and $u L u<0$ in $G$. Then for all $w \in \Omega$ for which $w=0$ on $\partial G$,

$$
\int_{G}\left\{\left[\mathrm{~A}^{i j}(x) D_{i j} w\right]^{2}+B^{i j}(x) D_{i} w D_{j} w\right\} d x \geqq \int_{G} p(x) w^{2} d x,
$$

where equality holds if, and only if, $w \equiv k u$.

With the help of the Wirtinger-type inequality (19) we can now give a very simple proof of a Sturmian comparison theorem between two fourth order elliptic equations of the form (18). To this end we let $A_{0}=\left(A_{0}^{i j}\right)$ and $B_{0}=\left(B_{0}^{i j}\right)$ be real symmetric matrix functions of class $C^{2}(\bar{G} \times R)$ and $C^{1}(\bar{G} \times R)$ respectively and let $p \in C(\bar{G} \times R)$. We shall compare (18) with

$$
D_{h i}\left[A_{0}{ }^{h i}\left(A_{0}^{j k} D_{j k} w\right)\right]-D_{i}\left(B_{0}^{i j} D_{j} w\right)-p_{0} w=0 .
$$

We take as boundary conditions for (22) either

$$
w=w_{\alpha_{0}}=0 \text { on } \partial G, \text { where } w_{\alpha_{0}}=\eta_{i} A_{0}^{i j} D_{j} w,
$$

or

$$
w=L_{0} w=0 \text { on } \partial G \text {, where } L_{0} w=A_{0}^{i j} D_{i j} w \text {. }
$$

Theorem 6. Let $A_{0}$ and $A$ be positive definite and let $B$ be positive semifinite. Suppose $u$ is a solution of (18) such that $L u<0$ whenever $u(x)>0$ in $G$. If there exists a nontrivial solution $w$ of (22) subject to either (23a) or (23b) such that

$$
\begin{aligned}
V(w, u)= & \int_{G}\left[(L w)^{2}-\left(L_{0} w\right)^{2}+\nabla w \cdot\left(B-B_{0}\right) \nabla w\right. \\
& \left.+\left(p_{0}-p\right) w^{2}\right] d x \leqq 0,
\end{aligned}
$$

then $u$ must have a zero in $G$ unless $w \equiv k u$.

Proof. Suppose the contrary and let $u$ be a solution of (18) such that $u(x)>0$ in $G$. Since $w=0$ on $\partial G$ by (23), the solution $w$ of (22) is clearly in $\Omega$ so that inequality (19) must hold for this particular choice of $w$. On the other hand if we multiply (22) by $w$, we can integrate the first two terms by means of the divergence theorem and the identities 


$$
\begin{gathered}
D_{h}\left[w D_{i}\left(L_{0} w A_{0}^{h i}\right)\right]=D_{h} w D_{i}\left[\left(L_{0} w\right) A_{0}^{h i}\right]+w D_{h i}\left[\left(L_{0} w\right) A_{0}^{h i}\right], \\
\nabla \cdot\left(w B_{0} \nabla w\right)=\nabla w \cdot B_{0} \nabla w+w \nabla \cdot\left(B_{0} \nabla w\right),
\end{gathered}
$$

and

$$
D_{i}\left[\left(L_{0} w\right) A_{0} \nabla w\right]=\nabla w \cdot D_{i}\left[\left(L_{0} w\right) A^{h i}\right]+\left(L_{0} w\right)^{2} .
$$

The resulting expression after integration is

$$
\int_{G}\left[\left(L_{0} w\right)^{2}+\nabla w \cdot B_{0} \nabla w-p_{0} w^{2}\right] d x=0 .
$$

Adding this to (19) we get $V(w, u) \geqq 0$ which contradicts (24) unless $V=0$. However, this latter condition means equality must hold in (19), i.e., $w \equiv k u$. This proves the theorem.

In view of Remark 1 following Theorem 4 we can also state the above comparison theorem for subsolutions and supsolutions.

Corollary 7. Let $A_{0}, A$ and $B$ be positive semidefinite. Suppose $u$ is a nonnegative solution of

$$
\left\{\begin{array}{l}
D_{h i}\left[A^{h i}\left(A^{j k} D_{j k} u\right)\right]-D_{i}\left(B^{i j} D_{j} u\right)-p u \geqq 0, \quad x \in G \\
L u=0, \quad x \in \partial G
\end{array}\right.
$$

such that $L u \leqq 0$ in $G$. If there exists a nonnegative nontrivial solution $w$ of

$$
D_{h i}\left[A_{0}^{h i}\left(A_{0}^{j k} D_{j k} w\right)\right]-D_{i}\left(B_{0}^{i j} D_{j} w\right)-p_{0} w \leqq 0
$$

subject to either (23a) or (23b) such that $V(w, u) \leqq 0$, then $u$ must have a zero in $G$, provided strict inequality holds in either (27) or (28) for at least one interior point of $G$ and $w$ does not vanish on any open subset of $G$.

Proof. In place of (26) we now have the inequality

$$
\int_{G}\left[\left(L_{0} w\right)^{2}+\nabla w \cdot B_{0} \nabla w-p_{0} w^{2}\right] d x \leqq 0 .
$$

The assumption that strict inequality holds in either (27) or (28) for at least one interior point of $G$ and that $w$ does not vanish on any open subset of $G$ imply strict inequality must hold in either (19) or $\left(26^{\prime}\right)$. Thus we must have

$$
V(w, u)>0
$$

which is the desired contradiction.

REmark 5. Suppose the coefficients $A, A_{0}, B$ and $B_{0}$ are functions 
of $x$ alone. Let

$$
\bar{V}(w)=\int_{G}\left\{(L w)^{2}-\left(L_{0} w\right)^{2}+\nabla w \cdot\left(B-B_{0}\right) \nabla w+w^{2}\left[p_{0}(x, w)-p(x, w)\right]\right\} d x
$$

and

$$
E(u, w)=\int_{G} w^{2}[p(x, w)-p(x, u)] d x
$$

Then (29) may be rewritten as

$$
\bar{V}(w)+E(u, w)>0
$$

Under the hypotheses of Corollary 7, if the system (28) + (23a) or (23b) has a nonnegative nontrivial solution $w$ which does not vanish on any open subset of $G$ and that $\bar{V}(w) \leqq 0$, then every solution $u$ of (27) which is positive in $G$ satisfies $E(u, w)>0$. This observation extends a result of Swanson ([16], Theorem 1) to fourth order quasilinear equations. In fact, by taking $A=A_{0} \equiv 0$ and $B$ to be positive definite, his result also follows from $\left(29^{\prime}\right)$.

REMARK 6. When the equation is linear then inequality (19') can be used in place of (19) in the derivation of a comparison theorem. In this case we can restate Theorem 6 as follows:

Corollary 8. Suppose equations (18) and (22) are linear. Let $A_{0}$ and $A$ be positive definite and let $B$ be positive semidefinite in $G$. Suppose there exists a nontrivial solution $w$ of $(22)$ subject to either (23a) or (23b) such that

$$
V(w)=\int_{G}\left[(L w)^{2}-\left(L_{0} w\right)^{2}+\nabla w \cdot\left(B-B_{0}\right) \nabla w+\left(p_{0}-p\right) w^{2}\right] d x \leqq 0 .
$$

Then every solution $u$ of (18) such that $u L u<0$ whenever $u(x) \neq 0$ in $G$ must have a zero in $G$ unless $w \equiv k u$.

In view of Remark 2, it is easy to see that Cor. 8 contains in particular a recent result of Diaz and Dunninger ([8], Theorem 3.1) on the linear fourth order equation

$$
\Delta^{2} u-p(x) u=0
$$

We conclude by extending Cor. 7 to the nonselfadjoint elliptic inequality (3). The comparison inequality will now be

$$
D_{h i}\left[A_{0}^{h i}\left(A_{0}^{j k} D_{j k} w\right)\right]-D_{i}\left(B_{0}^{i j} D_{j} w\right)-2 \sigma_{0}^{i} D_{i} w-p_{0} w \leqq 0
$$

where $\sigma_{0}=\left(\sigma_{0}^{1}, \cdots, \sigma_{0}^{n}\right)$ is a continuous vector field on $\bar{G} \times R$. Let $H$ denote the $(n+1) \times(n+1)$ matrix 


$$
H=\left(\begin{array}{lr}
B & -\sigma \\
-\sigma^{t} & g
\end{array}\right)
$$

and let $\tau=\left(\tau_{1}, \cdots, \tau_{n+1}\right)$ be a vector in $R^{n+1}$. We shall write

$$
M_{2}^{*}=\int_{G} \tau \cdot H \tau d x \text {. }
$$

THEOREM 9. Let $u$ be a nonnegative solution of (3) such that $L u<0$ in $G$ and $L u=0$ on $\partial G$. Let $A_{0}, A$ and $B$ be positive definite and let $g$ be a real continuous function on $\bar{G}$ for which

$$
\operatorname{det} H \geqq 0 \text {. }
$$

Suppose there exists a nontrivial nonnegative solution $w$ of (30) satisfying either (23a) or (23b) such that

$$
\begin{aligned}
N(w, u)= & \int_{G}\left[(L w)^{2}-\left(L_{0} w\right)^{2}+\nabla w \cdot\left(B-B_{0}\right) \nabla w\right] d x \\
& +\int_{G}\left[2 w \nabla w \cdot\left(\sigma_{0}-\sigma\right)+\left(g+p_{0}-p\right) w^{2}\right] d x<0 .
\end{aligned}
$$

Then $u$ must have a zero in $G$.

Proof. Suppose the contrary and let $u$ be a solution of (3) such that $u(x)>0$ throughout $G$. Then by Lemma 1 , the vector $v$ and the matrix $Z$ defined by (4) will together satisfy the Riccati inequation (5). It follows from Theorem 2 that inequality (12) must hold for all $w \in \Omega$. If we take in particular the solution $w$ of (30) then $w=0$ on $\partial G$ so that $\gamma(w, u)=0$ by $\left(11^{\prime}\right)$. As in the proof of Cor. 3, $M_{1} \geqq 0$ and $T \leqq 0$ so that (12) reduces to

$$
Q(w, u) \geqq M_{2}(w, v)+2 \int_{G} u^{-1} w^{2}(\sigma \cdot \nabla u) d x .
$$

If we let $\tau_{i}=\left(D_{i} w-w v_{i}\right), i=1, \cdots, n$ and let $\tau_{n+1}=w$, then we see from (8) that

$$
\begin{aligned}
Q(w, u) & \geqq \int_{G}\left[\left(D_{i} w-w v_{i}\right) B^{i j}\left(D_{j} w-w v_{j}\right)+2 u^{-1} w^{2}(\sigma \cdot \nabla u)\right] d x \\
& =\int_{G}\left[\tau_{i} B^{i j} \tau_{j}-2 \tau_{n+1} \sigma^{i} \tau_{i}+2 w \nabla w \cdot \sigma\right] d x
\end{aligned}
$$

If we add the integral of $g w^{2}$ to both sides and rearrange terms using (31), we find that

$$
\begin{aligned}
& \int_{G}\left[(L w)^{2}+\nabla w \cdot B \nabla w-2 w \nabla w \cdot \sigma+(g-p) w^{2}\right] d x \\
\geqq & \int_{G} \tau \cdot H \tau d x=M_{2}^{*} .
\end{aligned}
$$


It is known [14] that condition (32) is both necessary and sufficient for the matrix $H$ to be positive semidefinite so that $M_{2}^{*} \geqq 0$. Hence

$$
\int_{G}\left[(L w)^{2}+\nabla w \cdot B \nabla w-2 w \nabla w \cdot \sigma+(g-p) w^{2}\right] d x \geqq 0 .
$$

On the other hand if we multiply (30) by $w$ and integrate the first two terms with the help of identities (25), we get

$$
\int_{G}\left[\left(L_{0} w\right)^{2}+\nabla w \cdot B_{0} \nabla w-2 w \nabla w \cdot \sigma_{0}-p_{0} w^{2}\right] d x \leqq 0 .
$$

Combining this with (33) we arrive at $N(w, u) \geqq 0$ which is the desired contradiction.

Recently Kreith [12] has given a comparison theorem for nonselfadjoint ordinary differential equations of the fourth order using a Picone type identity. Dunninger [9] has also obtained a Picone type identity for linear fourth order elliptic equations which leads to comparison theorems similar to those given here. The Riccati transformation (4) may be applied to other fourth order elliptic inequalities. The continuity requirement on the coefficients can be weakened from $\bar{G}$ to $G$ to allow for operators with singular boundaries, c.f. Kreith [11]. Such problems can be handled by a limiting procedure similar to that used in [18].

Finally, we remark that as in [1] and [2], the Wirtinger-type inequalities and comparison theorems given here can be used to generate oscillation criteria for fourth order elliptic inequalities.

ACKNowledgement. This work was done while the author was visiting the Mathematical Institute, Tôhoku University, Sendai, Japan. The author wishes to thank Professors Taro Yoshizawa and Junji Kato, and members of the Institute for their warm hospitality and the many helpful conversations.

\section{REFERENCES}

1. W. Allegretto, Oscillation criteria for fourth order elliptic operators, Boll. Un. Mat. Ital., 3 (1970), 357-361.

2. W. Allegretto and C. A. Swanson, Oscillation criteria for elliptic systems, Proc. Amer. Math. Soc., 27 (1971), 325-330.

3. P. R. Beesack, Integral inequalities of the Wirtinger type, Duke Math. J., 25 (1958), 477-498.

4. D. C. Benson, Inequalities involving integrals of functions and their derivatives,

J. Math. Anal. Appl. 17 (1967), 292-308.

5. J. Calvert, An integral inequality with applications to the Dirichlet problem, Pacific

J. Math., 22 (1967), 19-29. Correction, Ibid., 23 (1967), 631.

6. - Integral inequalities involving second order derivatives, Pacific J. Math., 27 (1968), 39-47. 
7. W. J. Coles, Wirtinger-type integral inequalities, Pacific J. Math., 11 (1961), 871877.

8. J. B. Diaz and D. R. Dunninger, Sturm separation and comparison theorems for a class of fourth order ordinary and partial differential equations, to appear.

9. D. R. Dunninger, A Picone identity for fourth order elliptic differential equations with applications, to appear.

10. G. H. Hardy, J. E. Littlewood, and G. Polya, Inequalities, 2nd ed., Cambridge University Press, Cambridge, 1952.

11. K. Kreith, Oscillation theorems for elliptic equations, Proc. Amer. Math. Soc., 15 (1964), 341-344.

12. - A Picone identity for first order differential systems, J. Math. Anal. Appl., 31, (1970), 297-308.

13. M. H. Protter and H. F. Weinberger, Maximum Principles in Differential Equations, Prentice-Hall, Englewood Cliffs, N. J., 1967.

14. C. A. Swanson, A comparison theorem for elliptic differential equations, Proc. Amer. Math. Soc., 17 (1966), 611-616.

15. - A generalization of Sturm's comparison theorem, J. Math. Anal. Appl., 15 (1966), 512-517.

16. Comparison theorems for quasilinear elliptic differential inequalities, J. Differential Equations, 7 (1970), 243-250.

17. Pui-Kej Wong, Wirtinger type inequalities and elliptic differential inequalities, Tôhoku Math. J., 23 (1971), 117-128.

18. - A Sturmian theorem for first order partial differential equations, Trans. Amer. Math. Soc., to appear.

Received January 28, 1971, and in revised form June 1, 1971.

Michigan State University 



\section{PACIFIC JOURNAL OF MATHEMATICS}

\section{EDITORS}

\section{H. SAMELSON}

Stanford University

Stanford, California 94305

\section{R. HOBBY}

University of Washington Seattle, Washington 98105

\section{J. DugundJI}

Department of Mathematics University of Southern California Los Angeles, California 90007

RICHARD ARENS

University of California Los Angeles, California 90024

\section{ASSOCIATE EDITORS}
E. F. BECKENBACH
B. H. Neumann
F. WoLF
K. YoSHIDA

\section{SUPPORTING INSTITUTIONS}

UNIVERSITY OF BRITISH COLUMBIA CALIFORNIA INSTITUTE OF TECHNOLOGY

UNIVERSITY OF CALIFORNIA

MONTANA STATE UNIVERSITY

UNIVERSITY OF NEVADA

NEW MEXICO STATE UNIVERSITY

OREGON STATE UNIVERSITY

UNIVERSITY OF OREGON

OSAKA UNIVERSITY

\author{
UNIVERSITY OF SOUTHERN CALIFORNIA \\ STANFORD UNIVERSITY \\ UNIVERSITY OF TOKYO \\ UNIVERSITY OF UTAH \\ WASHINGTON STATE UNIVERSITY \\ UNIVERSITY OF WASHINGTON \\ * * * * \\ AMERICAN MATHEMATICAL SOCIETY \\ NAVAL WEAPONS CENTER
}

The Supporting Institutions listed above contribute to the cost of publication of this Journal, but they are not owners or publishers and have no responsibility for its content or policies.

Mathematical papers intended for publication in the Pacific Journal of Mathematics should be in typed form or offset-reproduced, (not dittoed), double spaced with large margins. Underline Greek letters in red, German in green, and script in blue. The first paragraph or two must be capable of being used separately as a synopsis of the entire paper. The editorial "we" must not be used in the synopsis, and items of the bibliography should not be cited there unless absolutely necessary, in which case they must be identified by author and Journal, rather than by item number. Manuscripts, in duplicate if possible, may be sent to any one of the four editors. Please classify according to the scheme of Math. Rev. Index. to Vol. 39. All other communications to the editors should be addressed to the managing editor, Richard Arens, University of California, Los Angeles, California, 90024.

50 reprints are provided free for each article; additional copies may be obtained at cost in multiples of 50 .

The Pacific Journal of Mathematics is published monthly. Effective with Volume 16 the price per volume (3 numbers) is $\$ 8.00$; single issues, $\$ 3.00$. Special price for current issues to individual faculty members of supporting institutions and to individual members of the American Mathematical Society: $\$ 4.00$ per volume; single issues $\$ 1.50$. Back numbers are available.

Subscriptions, orders for back numbers, and changes of address should be sent to Pacific Journal of Mathematics, 103 Highland Boulevard, Berkeley, California, 94708.

PUBLISHED BY PACIFIC JOURNAL OF MATHEMATICS, A NON-PROFIT CORPORATION

Printed at Kokusai Bunken Insatsusha (International Academic Printing Co., Ltd.), 270, 3-chome Totsuka-cho, Shinjuku-ku, Tokyo 160, Japan. 


\section{Pacific Journal of Mathematics}

\section{Vol. 40, No. $3 \quad$ November, 1972}

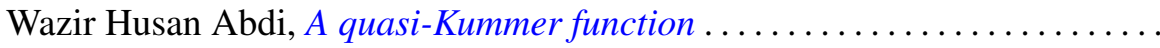

Vasily Cateforis, Minimal injective cogenerators for the class of modules of

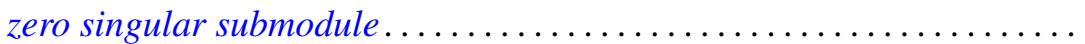

W. Wistar (William) Comfort and Anthony Wood Hager, Cardinality of

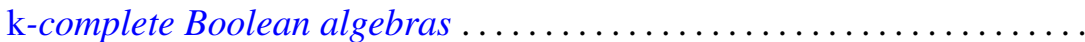

Richard Brian Darst and Gene Allen DeBoth, Norm convergence of martingales of Radon-Nikodym derivatives given a $\sigma$-lattice ..........

M. Edelstein and Anthony Charles Thompson, Some results on nearest points and support properties of convex sets in $c_{0} \ldots \ldots \ldots \ldots \ldots$

Richard Goodrick, Two bridge knots are alternating knots .

Jean-Pierre Gossez and Enrique José Lami Dozo, Some geometric properties related to the fixed point theory for nonexpansive mappings ..........

Dang Xuan Hong, Covering relations among lattice varieties .............

Carl Groos Jockusch, Jr. and Robert Irving Soare, Degrees of members of $\Pi_{1}^{0}$

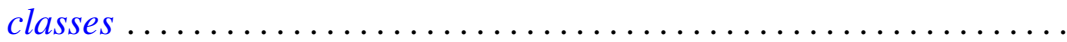

565

575

605

Leroy Milton Kelly and R. Rottenberg, Simple points in pseudoline

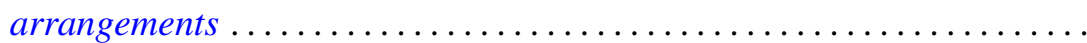

Joe Eckley Kirk, Jr., The uniformizing function for a class of Riemann surfaces....

Glenn Richard Luecke, Operators satisfying condition $\left(G_{1}\right)$ locally ... 629

T. S. Motzkin, On L $(S)$-tuples and l-pairs of matrices ... . .

Charles Estep Murley, The classification of certain classes of torsion free

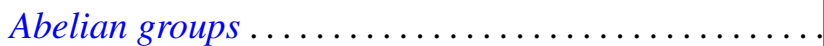

Louis D. Nel, Lattices of lower semi-continuous functions and associated topological spaces.

David Emroy Penney, II, Establishing isomorphism between tame prime

knots in $E^{3}$. . .

Daniel Rider, Functions which operate on $\mathscr{F} L_{p}(T), 1<p<2$

Thomas Stephen Shores, Injective modules over duo rings ...

Stephen Simons, A convergence theorem with boundary. .

703

Stephen Simons, Maximinimax, minimax, and antiminimax theorems and a

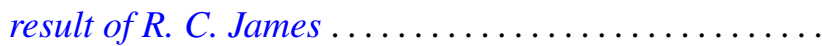

Stephen Simons, On Ptak's combinatorial lemma ........

Stuart A. Steinberg, Finitely-valued $f$-modules............

Pui-kei Wong, Integral inequalities of Wirtinger-type and fourth-order

elliptic differential inequalities .

Yen-Yi Wu, Completions of Boolean algebras with partially additive

operators ..................................

Phillip Lee Zenor, On spaces with regular $G_{\delta}$-diagonals . . . 